\title{
Experimental and Numerical Investigation of the Drying of an Agricultural Soil
}

\author{
Njaka Ralaizafisoloarivony ${ }^{1}$, Kien Tran $^{1,2}$, Aurore Degré ${ }^{1}$, Benô̂t Mercatoris ${ }^{1}$, Angélique Léonard $^{3}$, Dominique Toye ${ }^{3}$, and \\ Robert Charlier,"*
}

${ }^{1}$ University of Liège, Gembloux Agro-Bio Tech, 5030 Gembloux, Belgium

${ }^{2}$ University of Liège, Department ArGEnCo, Quartier POLYTECH 1, 4000 Liège, Belgium

${ }^{3}$ University of Liège, Chemical Engineering, 4000 Liège, Belgium

\begin{abstract}
Due to climate change, soil desiccating became a serious concern in the agricultural area of Belgium. Knowing soil evaporation kinetic can help to elucidate and predict: the soil moisture regime, soil water retention and soil water content. Those parameters are vital for water use efficiency and sustainable agriculture. This research investigated the mechanism of soil evaporation using both laboratory experiment and numerical simulation. Soil samples (Luvisol) were collected from the agricultural field in GemblouxBelgium, and tested in a small drying chamber. Sensors measured the chamber temperature and humidity, while digital camera monitored the soil surface throughout the experiment. HYPROP device recorded the water change, soil suction, and soil water retention curve. During three evaporation experiments, four periods were observed rather than three as commonly recorded in the theory of drying. The modelling considered thermo-hydro-mechanical framework for predicting the drying process of Luvisol. The model used the finite element code LAGAMINE created at the University of Liege. The software aims at assessing the mechanism of water transport between soil and atmosphere. The results of the simulation showed major domination of Darcean flow during desiccating, while some short vapour diffusion occurred only after the soil surface began to de-saturate.
\end{abstract}

\section{Introduction}

The process of evaporation is quite complicated in agricultural soil since it is conditioned by the soil characteristics (textures, structure, etc.), soil management (tillage, covered crop, etc.), and the environmental condition (precipitation, temperature, etc.). The increase of the world temperatures raised the soil evaporation rate, leading to severe crop water stress and considerable yield loss. In Belgium, several dry spells (no rainfall) were recorded over the course of the $21^{\text {st }}$ century [1]. Understanding the kinetic of evaporation of the Luvisol (soil of Belgium) will help to find appropriate method to enhance water use efficiency and alleviate the effect of climate change on plant water stress.

Based on previous studies, three distinct periods of evaporation occurred during the process of drying [2]. The first period is a Constant Rate Period (CRP) during which the evaporation rate is at its highest and constant. When the soil water supply decreases, there is prompt drop of the soil evaporation called "critical-moisture content", indicating the start of the first Falling Rate Period (FRP 1) [3, 4]. The soil surface starts to dry drastically till the third period called second Falling Rate Period (FRP 2). The evaporation is very low due to strong interacting forces at the soil liquid-solid interface.
Despite wide knowledge of the process, it is not well understood if the soil water evaporation is mainly due to liquid transport by capillary or by gas diffusion transport. Moreover, the soil characteristics and its behaviour will play huge roles in this mechanism $[5,6]$.

In general, there is a complex soil hydro-thermomechanical behaviour. Any change in soil temperature, shrinkage, porosity, etc. affects the soil water evaporation. Those in turn impact the water suction, water content, contaminant transport, available water for plant etc. [7, 8]. Previous numerical estimation model assessed the drying mechanism at pore level (ex: Pore network Model). They were limited to isothermal condition and non-deformable sample due to the need for high speed computer [9]. Continuum models were commonly used for evaporation test [10,11]. Gerard et al. [12] coupled hydro-thermal conditions to simulate convective drying of a silt soil. Prime et al. [13] and An et al. [14] used the same method for limestone and sand, respectively. The mechanical parameter was also added to the model in order to properly describe the shrinkage of the sampled material $[15,16]$. This study used agricultural soil and considered water flow (hydro-), temperature (thermo-) and soil shrinkage (mechanical) to model the kinetic of evaporation. 


\section{Materials and Methods}

\subsection{Sampling}

Three samples of soils were taken from $0-10 \mathrm{~cm}$ depth from an agricultural site in Gembloux-Belgium. The soil was a Cutanic Luvisol based on FAO soil classification [17] and contained about $70 \%$ silt, $20 \%$ clay and $10 \%$ sand. The bulk density and specific gravity of the undisturbed soil were $1.38 \mathrm{~g} \mathrm{~cm}^{-3}$ and $2.65 \mathrm{~g} \mathrm{~cm}^{-3}$ respectively. The same soil was oven dried (at $40^{\circ} \mathrm{C}$ for one week), crushed, sieved at $2 \mathrm{~mm}$, and gradually compressed (dry) on three core rings $(5 \mathrm{~cm}$ height $\mathrm{x} 8 \mathrm{~cm}$ diameter) to form the original bulk density. Those three disturbed samples were used during the study.

\subsection{Device preparation and analysis}

Drying experiment was conducted in a drying chamber using HYPROP device (UMS GmbH, Munich, Germany). The device was very accurate for continuous measurement of water evaporation, matrix suction (from $0-100 \mathrm{kPa}, 2 \%$ accuracy) and soil water content.

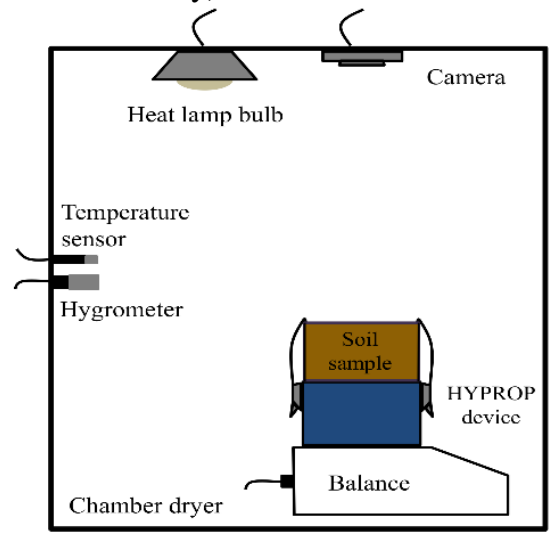

Fig. 1.Drying chamber of the experiment

The samples were saturated for $24 \mathrm{~h}$ and inserted on the HYPROP package. The soil surface was exposed to a free evaporation. Precision balance $(0.01 \mathrm{~g})$ monitored the soil weight (Figure 1). Temperature and relative humidity were measured with Platinum resistance thermometer $\left(0.1^{\circ} \mathrm{C}\right.$ accuracy) and DHT22 sensors (2$5 \%$ accuracy), respectively. A Canon digital camera (12 Mpixel, 5\% accuracy), placed $0.5 \mathrm{~m}$ above the sample, monitored the soil shrinkage. All data was recorded every one min except for the camera (30 min). The HYPROP package came with hydraulic models to fit the data including: Mualem, Van Genuchten, Durner models, etc. For the evaporation prediction, the model used was the LAGAMINE code [18] with Finite Element Method. It predicted the process of moisture transfer between the soil surface and the ambient.

\section{Experimental results}

The evaporation rate was observed through the water loss per surface unit and over time:

$$
\bar{q}=-\frac{1}{A} \frac{d m}{d t}
$$

Where: $m[\mathrm{~kg}]$ and $A\left[\mathrm{~m}^{2}\right]$ were the mass and surface area, respectively. Figure 2 showed the soil evaporation rate over time. All three tests presented high fluctuation during the first hour of the experiment, but depicted rather similar trend for the rest of it.

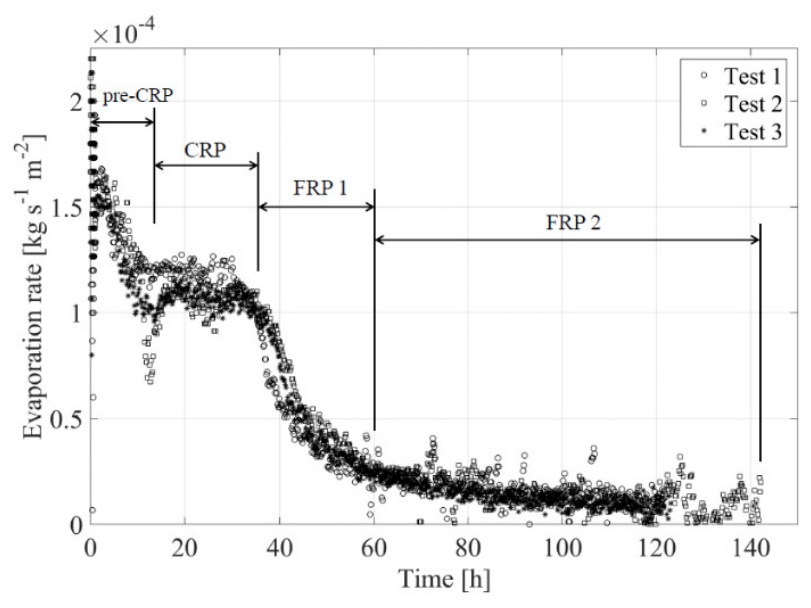

Fig. 2. Change of evaporation rate with time

Four distinct periods of evaporation were observed. Figure 2 presented a pre-CRP period during the first $15 \mathrm{~h}$ which was characterised by high evaporation rate attaining $1.2 \times 10^{-4} \mathrm{~kg} \mathrm{~s}^{-1} \mathrm{~m}^{-2}$. This was due to the excess of water in the beginning and the pre-heating of the chamber. The second period CRP occurred when the evaporation attained around $10^{-4} \mathrm{~kg} \mathrm{~s}^{-1} \mathrm{~m}^{-2}$. The CRP lasted for about $20 \mathrm{~h}$, passed through a "critical-moisture content", then continued to the third period (FRP1) when the evaporation rate declined. The sample surface experienced a rapid drying. The beginning of the last period FRP2 was observed as soon as the evaporation rate arrived at its lowest.

\subsection{Soil temperature evolution}

Figures 3 showed the temperature above and below the samples (illustration of test 3).

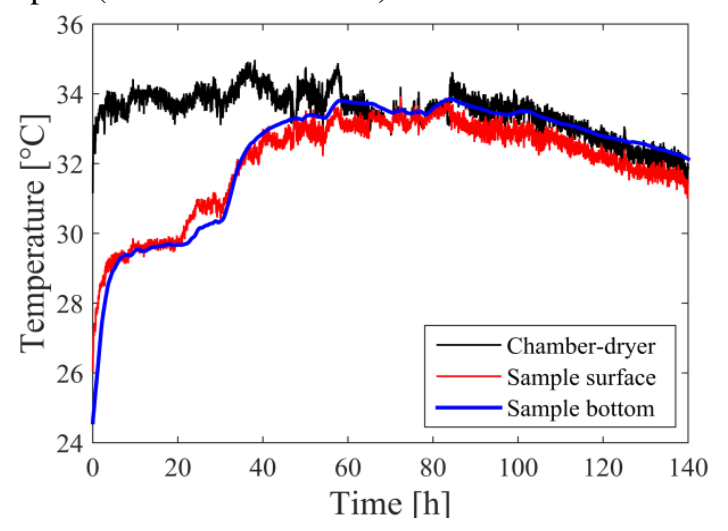

Fig. 3. Soil temperature evolution with time (test 3)

During the pre-CRP, the bottom and the surface temperatures increased at the same rate. Temperatures were almost constant throughout the CRP periods. Since 
the evaporation rate was constant, the result indicated that the applied heat was compensated proportionately by the heat consumed to produce vapour. When there is not enough water vapour during FRP, the soil temperature raised to reach the ambient temperature. Similar result was found by Kowalski [19]. He observed that the stagnant temperature during CRP was the wetbulb temperature obtained from the relation proposed by Stull [20]. Based on the relation, the calculated wet-bulb temperatures of our samples were $19.1,19.7$ and $21.3^{\circ} \mathrm{C}$, respectively.

\subsection{Shrinkage}

The shrinkage was observed from sequenced images taken from fixed camera. Image J software converted the coloured image into gray 8-bit and in binary images. The expansion of the black pixels of the binary images represented the soil shrinkage [21]. The shrinkage was expressed in percentage of the areas of black pixels over the sample total surface. Figure 4 showed that the soil surfaces were reduced by $6.7 \%, 5.1 \%$, and $6.2 \%$, for the three samples. The shrinkage took place during the preCRP. More than $70 \%$ of the shrinkage occurred during the time the degree of saturation was quite high $(>0.75)$.

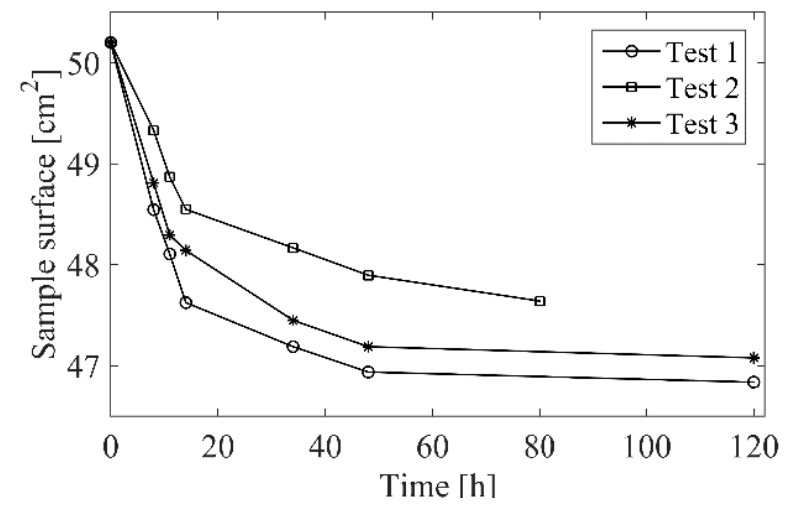

Fig. 4. Soil surface shrinkage with time

\section{Coupled thermo-hydro-mechanical model}

\subsection{Mechanical model}

Soil mechanical properties (i.e. stiffness modulus) were related to soil moisture content [22, 23, 24]. The results showed an increase of soil (stiffness) modulus with matric suction. The relationship shrinkage degree of saturation was nonlinear; therefore, we choose a nonlinear elastic mechanical model. Bishop's effective stress was used.

$$
\sigma_{i j}^{\prime}=\sigma_{i j}-p_{g} \delta_{i j}+S_{r}\left(p_{g}-p_{w}\right) \delta_{i j}
$$

Where: $\sigma_{\mathrm{ij}}^{\prime}$ effective stress tensor, $\sigma_{\mathrm{ij}}$ total stress tensor, $S_{r}$ degree of saturation, $\delta_{i j}$ Kronecker's tensor, $p_{w}$ and $p_{g}$ water and gas pressure.
In order to reproduce the nonlinear behaviour of the soil, equation 6 related the stiffness modulis to the suction $p_{c}=p_{g}-p_{w}$

$$
\begin{gathered}
\sigma_{i j}^{\prime}=D_{i j k l}^{e} \varepsilon_{i j} \\
D_{i j k l}^{e}=2 G \delta_{i k} \delta_{j l}+\left(K-\frac{2}{3} G\right) \delta_{i j} \delta_{k l} \\
G=\frac{3(1-2 v)}{2(1+v)} K \\
K=\frac{K_{0}}{3(1-2 v)}\left\{\left(k_{1}-1\right)\left[1-\exp \left(-k_{2} p_{c}\right)\right]+1\right\}
\end{gathered}
$$

Where: $\mathrm{D}_{\mathrm{ijkl}}^{\mathrm{e}}$ global elastic tensor, $\varepsilon_{\mathrm{ij}}$ elastic strain, $K$ and $G$ bulk and shear moduli, $v$ Poisson's ratio of the porous medium, $\mathrm{K}_{0}$ initial value of the bulk modulus, $\mathrm{k}_{1}$ and $k_{1}$ are fitting parameters, $p_{c}$ suction.

\subsection{Hydraulic model}

The fluid transport was predicted by a biphasic flow model as follow. The advective fluxes of liquid and gas were determined by Darcy's law. We assumed that the media were non-reactive material, so that water and gas flow depended on the degree of saturation $\left(S_{r}\right)$ only. $S_{r}$ was determined from the water stored in porous medium and the suction $p_{c}$, and calculated from the dual porosity model of Durner [25].

$$
\begin{gathered}
q_{w}=-\frac{k_{w}}{\mu_{w}}\left(\nabla p_{w}+\rho_{w} g\right) \\
q_{g}=-\frac{k_{g}}{\mu_{g}}\left(\nabla p_{g}+\rho_{g} g\right) \\
S_{r}=S_{r e s}+\left(S_{s a t}-S_{r e s}\right)\{w_{1} \underbrace{\left[1+\left(\alpha_{1} p_{c}\right)^{-n_{1}}\right]^{m_{1}}}_{S_{e 1}}+ \\
w_{2} \underbrace{\left[1+\left(\alpha_{2} p_{c}\right)^{-n_{2}}\right]^{m_{2}}}_{S_{e 2}}\}
\end{gathered}
$$

Where: $q_{w}$ and $q_{g}$ mass fluxes of liquid and gas, $\rho_{w}$ and $\rho_{g}$ water and gas density, $g$ acceleration due to gravity, $k_{w}$ and $k_{g}$ water and gas permeability, $\mu_{w}$ and $\mu_{g}$ dynamic viscosities water and gas, $w_{1,2}$ weighing factors, $\alpha_{1,2}$ inverse of air entry pressure, $S_{s a t}$ and $S_{\text {res }}$ water maximal saturation and the water residual saturation, $S_{e 1,2}$ effective saturation, $m_{1,2}$ and $n_{1,2}$ model parameters, $m_{1,2}=1 / n_{1,2}$.

Adopting this water retention with the formulation proposed by Mualem [26], we obtained the hydraulic function $k_{W}$. The diffusive flux followed the Fick's law.

$$
\begin{gathered}
k_{w}=K_{w} \frac{\left(w_{1} S_{e 1}+w_{2} S_{e 2}\right)^{l}\left\{w_{1} \alpha_{1}\left[1-\left(1-S_{e l}^{\frac{1}{m_{l}}}\right)^{m_{l}}\right]+\right.}{\left(w_{1} \alpha_{1}+w_{2} \alpha_{2}\right)^{2}} \\
\frac{\left.w_{2} \alpha_{2}\left[1-\left(1-S_{e 2}^{\frac{1}{m_{2}}}\right)^{m_{2}}\right]\right\}^{2}}{\left(w_{1} \alpha_{1}+w_{2} \alpha_{2}\right)^{2}}
\end{gathered}
$$




$$
\begin{gathered}
i_{v}=-D_{v} \tau \varnothing\left(1-S_{r}\right) \nabla_{\rho v} \\
R H=\frac{\rho_{v}}{\rho_{v, \text { sat }}}=\exp \left(\frac{-p_{c} M_{v}}{\rho_{w} R T}\right) \\
\rho_{v, \text { sat }}=\{1994.4 \exp [-0.06374(T-273)+ \\
\left.\left.0.1634 \times 10^{-3}(T-273)^{2}\right]\right\}^{-1}
\end{gathered}
$$

Where: $K_{w}$ saturated water permeability, $l$ pore connectivity, $i_{v}$ diffusive flux by Fick's law, $D_{v}$ diffusion coefficient of vapour into dry air, $\tau$ and $\varnothing$ tortuosity and porosity, $\rho_{v}$ vapour density, $R H$ relative humidity, $M_{v}$ molecular mass of the water vapour, $R$ gas constant, $T$ temperature in Kelvin, $\rho_{v \text {,sat }}$ saturated vapour concentration.

\subsection{Heat transfer}

The heat transfer in porous media was governed by three mechanisms of transfer: - the heat conduction (Fourier's law), - the convective heat transfer (related to the flow of liquid, air and water vapour), - and an additional heat flux associated with the latent heat [9].

$V_{T}=$

$-\Gamma_{m} \nabla T+$

$\underbrace{\left[c_{p, w} \rho_{w} q_{w}+c_{p, a} \rho_{a} q_{g}+c_{p, w}\left(\rho_{a} q_{g}+i_{v}\right)\right]\left(T-T_{0}\right)}_{\text {convection }}+$

$\underbrace{\left(\rho_{v} q_{g}+i_{v}\right) L}_{\text {latent }}$

(Where: $c_{p, w} / c_{p, a} / c_{p, v}$ water/air/vapour specific heats, $\rho_{a}$ air density, $i_{v}$ diffusive flux of water vapour, $T_{0}$ initial temperature, $L$ water evaporation latent heat)

\subsection{Thermo-hydraulic boundary condition}

The simulation was performed on 2D-axisymetric cylindrical soil subdivided in 20 x 50 mesh elements. The boundary considered the transfer between the thin layers of soil surface and the ambient (Figure 5). The sample was saturated and only the upper soil surface allowed water to pass. The vapour flow and the heat transfer were due to vapour density difference and temperature difference between the ambient and the soil surface [27]. The radiant flux from the lamp-bulb and the air to the soil surface was estimated by the StefanBoltzmann equation.

$$
\begin{gathered}
\bar{q}=\alpha\left(\rho_{v, \text { sur } f}-\rho_{\text {v,air }}\right) \\
\bar{f}=L \bar{q}-\beta\left(T_{\text {air }}-T_{\text {surf }}\right)-R_{n} \\
R_{n}=\varepsilon_{s} \sigma A\left(T_{\text {air }}^{4}-T_{\text {surf }}^{4}\right)+R_{\text {lamp }}
\end{gathered}
$$

Where: $\bar{q}$ vapour flow, $\alpha$ mass transfer coefficient, $A$ surface area, $\rho_{v, \text { surf }}$ and $\rho_{v \text {,air }}$ vapour density soil surface and ambient, $\bar{f}$ heat flux, $\beta$ coefficient, $T_{\text {air }}$ and $T_{\text {surf }}$ temperature of soil ambiant and surface, $R_{n}$ net radiant from Stefan-Botlzmann law, $\varepsilon_{s}$ soil and bulb emissivity, $\sigma$ constant of Stefan-Boltzmann, $R_{\text {lamp }}$ flux term of lamp-bulb.

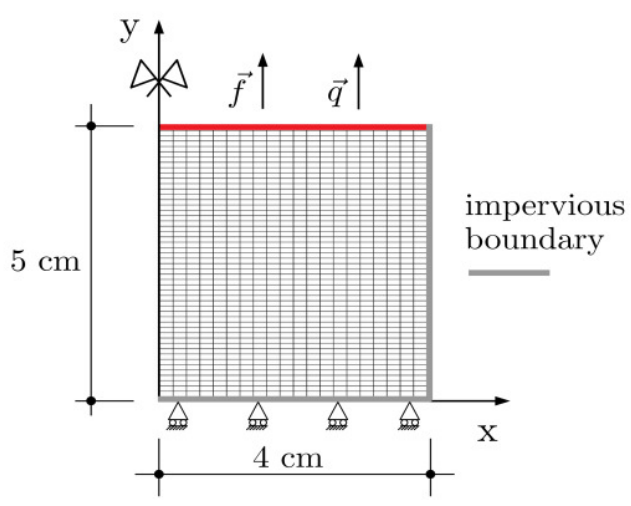

Fig. 5. Boundary condition of the model

\section{Numerical results and analysis}

\subsection{Parameters used in the simulation model}

Table 1, 2, 3 and 4 present all hydraulic, thermal, and mechanicals parameters used in the models. The model parameters were obtained from the experiments (Figure $3,4)$ and the HYPROP results. The predictive model was compared to the results from test 3 (Figure 6 to 11).

Table 1. Mass and heat transfer coefficients from experiments

\begin{tabular}{|c|c|c|}
\hline & $\alpha\left[\mathrm{ms}^{-1}\right]$ & $\beta\left[\mathrm{Wm}^{-2} \mathrm{~K}^{-1}\right]$ \\
\hline Test 1 & 0.0055 & 122.6 \\
\hline Test 2 & 0.0050 & 78.6 \\
\hline Test 3 & 0.0048 & 84.8 \\
\hline
\end{tabular}

Table 2. Parameters of the hydraulic model

\begin{tabular}{|c|c|c|}
\hline$\rho_{\mathrm{w}}\left[\mathrm{kgm}^{-3}\right]$ & Liquid water density & 1000 \\
\hline$\mu_{\mathrm{w}}[\mathrm{Pa} \cdot \mathrm{s}]$ & Water dynamic viscosity & $10^{-3}$ \\
\hline $\mathrm{K}_{\mathrm{w}}\left[\mathrm{m}^{2}\right]$ & Water permeability & $1.810^{-12}$ \\
\hline$\alpha_{1}\left[\mathrm{~cm}^{-1}\right]$ & $\begin{array}{c}\text { Inverse of air entry pressure } \\
\text { (macro-pores) }\end{array}$ & 0.1 \\
\hline$\alpha_{2}\left[\mathrm{~cm}^{-1}\right]$ & $\begin{array}{c}\text { Inverse of air entry pressure } \\
\text { (macro-pores) }\end{array}$ & 0.025 \\
\hline $\mathrm{m}_{1}[-]$ & Durner model parameter & 0.23 \\
\hline $\mathrm{m}_{2}[-]$ & Durner model parameter & 0.41 \\
\hline $\mathrm{S}_{\mathrm{res}}[-]$ & Residual water saturation & 0.004 \\
\hline
\end{tabular}


Table 3. Parameters of the thermal model

\begin{tabular}{|c|c|c|}
\hline$c_{p, w}\left[\mathrm{Jkg}^{-1} \mathrm{~K}^{-1}\right]$ & Liquid water specific heat & 4180 \\
\hline $\mathrm{c}_{\mathrm{p}, \mathrm{v}}\left[\mathrm{Jkg}^{-1} \mathrm{~K}^{-1}\right]$ & Water vapour specific heat & 1800 \\
\hline $\mathrm{c}_{\mathrm{p}, \alpha}\left[\mathrm{Jkg}^{-1} \mathrm{~K}^{-1}\right]$ & Air specific heat & 1000 \\
\hline$\Gamma_{\mathrm{m}}\left[\mathrm{Wm}^{-1} \mathrm{~K}^{-1}\right]$ & $\begin{array}{c}\text { Medium thermal } \\
\text { conductivity }\end{array}$ & 0.9 \\
\hline $\mathrm{L}\left[\mathrm{Jkg}^{-1}\right]$ & $\begin{array}{c}\text { Water evaporation latent } \\
\text { heat }\end{array}$ & 2500 \\
\hline
\end{tabular}

Table 4. Parameters of the mechanical model

\begin{tabular}{|c|c|c|}
\hline$\rho s\left[\mathrm{kgm}^{-3}\right]$ & Solid density & 2650 \\
\hline$\varnothing[-]$ & Porosity & 0.52 \\
\hline $\mathrm{K}_{0}[\mathrm{~Pa}]$ & Bulk modulus & $10^{5}$ \\
\hline $\mathrm{G}_{0}[\mathrm{~Pa}]$ & Shear modulus & $410^{-6}$ \\
\hline$v[-]$ & Poisson's ratio & 0.25 \\
\hline
\end{tabular}

\subsection{Soil shrinkage}

The non-linear elasticity law allowed predicting the soil stiffness and gave good agreement with the result with $\mathrm{R}^{2}=0.996$ (Figure 6). The shrinkage model presented in equation 6 fitted well the experimental result with soil bulk modulus $\mathrm{k}_{1}=1.210^{4}$ and $\mathrm{k}_{2}=510^{-8}$.

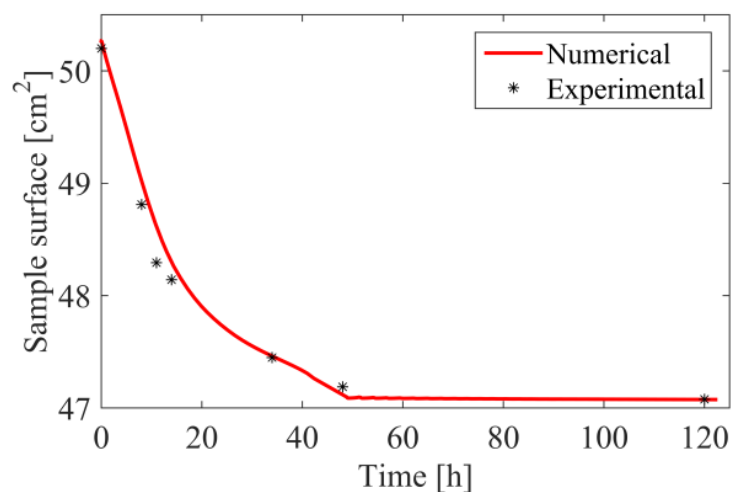

Fig. 6. Experimental and numerical surface shrinkage

\subsection{Kinetics of evaporation}

The numerical result of evaporation with degree of saturation and with time fit well with the experimental data except for the first period. The estimated evaporation rate of CRP coincided with the data. The high evaporation of the first period could not be reproduced due to the fact that the mass transfer coefficient between the surface and the ambient was obtained from the average evaporation rate in the CRP period. Therefore, it was not possible to get a coefficient value higher that during the CRP (Section 4.4).
However, the CRP period lasted longer and there was overestimation of evaporation during FRP period (Figure 7). In order to deal with the problem, high evaporation rate was introduced to the pre-CRP period (i.e. saturated state $\mathrm{Sr} \sim 0.8$ ), and then the prediction curve fit well the experimental data $\left(\mathrm{R}^{2}>0.9\right)$ (Figure 8).

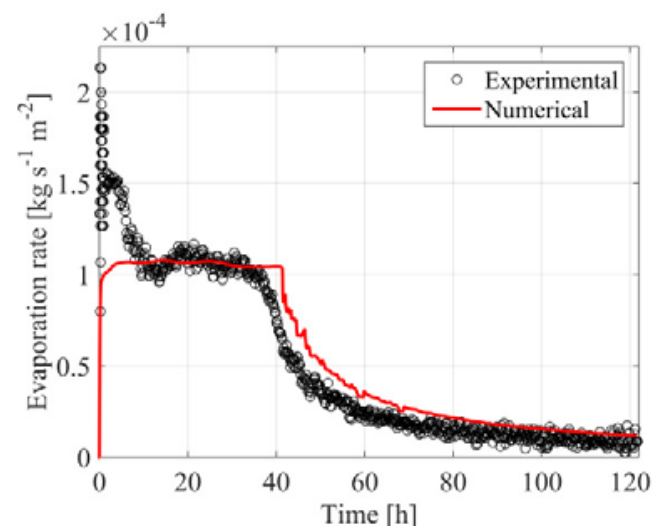

Fig. 7. Experimental and prediction of soil evaporation rate

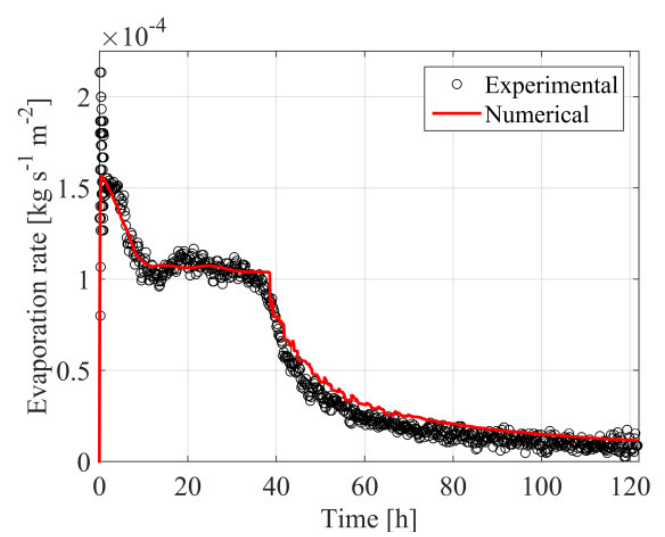

Fig. 8. Improved numerical prediction of soil evaporation rate

\subsection{Soil temperature}

The model managed to predict the temperature variation during the experiment. Temperature started from $28^{\circ} \mathrm{C}$ to the plateau of $32^{\circ} \mathrm{C}$ which was the wet-bulb temperature (Figure 9). The temperature increased during the period FRP and then reached the ambient temperature.

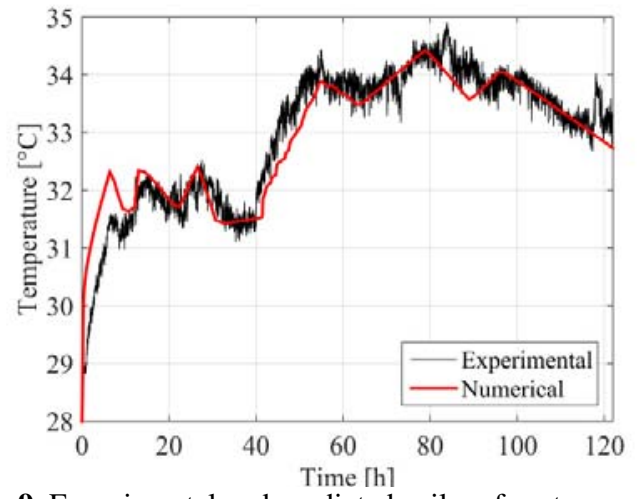

Fig. 9. Experimental and predicted soil surface temperature

\subsection{Water transfer}

The moisture transport during drying can be investigated 
based on Coussy [28] theory. It indicated that material with permeability below $10^{-19} \mathrm{~m}^{2}$ presented mainly Darcean advective water transport. Water was in liquid form and very negligible vapour diffusion. Therefore, the Luvisol was dominated by advective flow as its intrinsic permeability was of magnitude of $10^{-12} \mathrm{~m}^{2}$. Moreover, Figure 10 showed that moisture was mostly removed by Darcean advective flow. Figure 11 portrayed the humidity distribution in the sample. The entire sample has $100 \%$ relative humidity during saturation. There was formation of evaporation front (dry-and-wet front) when the soil start to de-saturate. The front moved to bottom as the soil kept on drying.

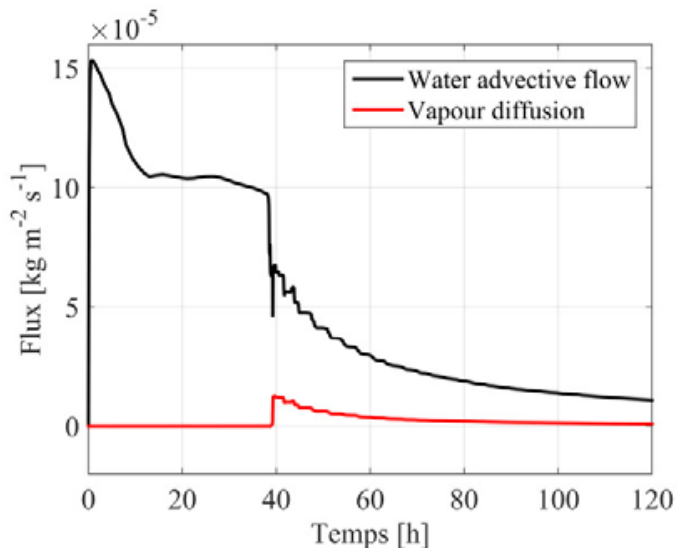

Fig. 10. Temporal evolution of water and vapour flow at the soil surface

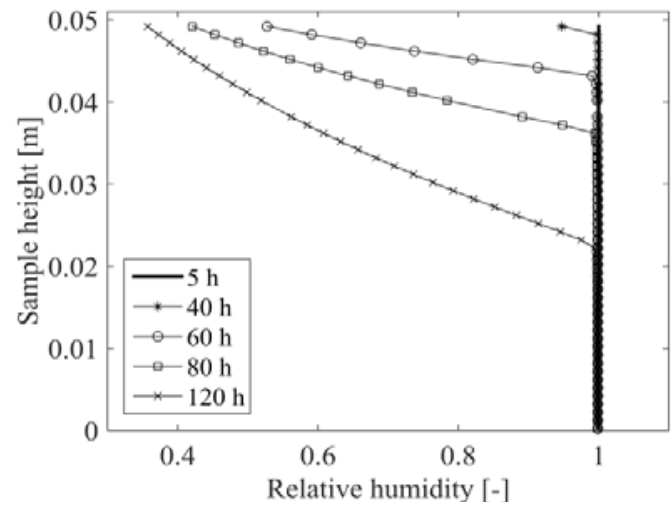

Fig. 11. Relative humidity profile along the sample with times

\section{Conclusion}

The study showed the process of evaporation of Luvisol in experimental and numerical approaches. Four evaporation periods were identified instead of three during the laboratory test. The soil temperature followed the Krischer's curve; however the wet-bulb temperature was higher due to the applied heat $\left(>30^{\circ} \mathrm{C}\right)$. The fully coupled thermal-hydraulic-mechanical model managed to reproduce the soil surface shrinkage, the temperature variation and the soil evaporation processes especially when correction was added during the start of evaporation. The moisture transfer mechanism of the agricultural Luvisol involved mainly Darcean advective flow. Vapour diffusion contributed a little during the entire process of evaporation. The evaporation front move from the soil surface to the bottom as the soil continued to dry.

\section{References}

1. R. Core, A. Pachauri, A.E. Reisinger (tech. rep., IPCC, 2007)

2. A. Léonard, S. Blacher, P. Marchot, J.P. Pirard, M. Crine, Dry. Tech., 23, 8 (2005)

3. R. Keey, M. Suzuki, Int. J. Heat. Mass. Tran. 17, 12 (1974)

4. W. Coumans, Chem. Eng. Pro. 39, 15 (2000)

5. X. Peng, R. Horn, Eur. J. Soil Sci. 58, 9 (2007)

6. M. Kutílek, Dev. Soil Sci. 24, 29 (1996)

7. J. Simunek, N. J. Jarvis, M. van Genuchten, A. Gärdenäs, J. Hydrol. 272, 21 (2003)

8. S. Das Gupta, B. P. Mohanty, J. M. Köhne, Soil Sci. Soc. Am. J. 70, 9 (2006)

9. Y. L. Bray, M. PratInt. J. Heat Mass Transf. 42, 17 (1999)

10. M. Suzuki and S. Maeda, J. Chem. Eng. Jpn. 1, 7 (1968)

11. M. Prat, Dry. Technol. 9, 27 (1991)

12. P. Gerard, A. Léonard, J.-P. Masekanya, R. Charlier, and F. Collin, Int. J. Numer. Anal. Methods Geomech. 34, 23 (2011)

13. N. Prime, Z. Housni, A. Léonard, R. Charlier, and S. Levasseur, Tran. Por. Med. 106, 25 (2015)

14. N. An, S. Hemmati, Y. J. Cui, and C. S. Tang, Eng. Geol. 234, 9 (2018)

15. J. Hubert, E. Plougonven, N. Prime, A. Léonard, and F. Collin, Int. J. Numer. Anal. Methods Geomech. 42, 19 (2017)

16. D. Gallipoli, S. Wheeler, and M. Karstunen. Geotech. 53, 1 (2003)

17. FAO, World reference base for soil (FAO, 2015)

18. F. Collin, X. Li, J. Radu, and R. Charlier, Eng. Geol. 64, 14 (2002)

19. S. J. Kowalski, Thermomechanics of Drying Processes (Springer, Berlin, Heidelberg, 2003)

20. R. Stull, J. Appl. Meteorol. Clim. 50, 2 (2011)

21. P. Singh, S. Rout and A. Tiwari. Int. J. Geo. Eng. 12,4 (2018)

22. T.B. Edil, S.E. Motan, Trans. Res. Rec. 705, 9 (1979)

23. D. Fredlund, A. Bergan, and P. Wong, Trans. Res. Rec. 8 (1977)

24. A. Sawangsuriya, T.B. Edil, P.J. Bosscher, J. Geotech. Geoenviron. 135, 13 (2009)

25. W. Durner, Water Resour. Res. 30, 12 (1994)

26. Y. Mualem, Water Resour. Res. 12, 9 (1976)

27. S. Nasrallah, P. Perre, J. Heat Mass Transf. 31, 10 (1988)

28. O. Coussy, Poromechanics (Wiley-Blackwell, 2005) 